\title{
Analysis of the coupled relationship between grain yields and agricultural labor changes in China
}

\author{
GE Dazhuan ${ }^{1,2,3}$, 'LONG Hualou ${ }^{1,3,4}$, ZHANG Yingnan $^{1,2,3}$, TU Shuangshuang ${ }^{1,5}$ \\ 1. Institute of Geographic Sciences and Natural Resources Research, CAS, Beijing 100101, China; \\ 2. University of Chinese Academy of Sciences, Beijing 100049, China; \\ 3. Center for Assessment and Research on Targeted Poverty Alleviation, CAS, Beijing 100101, China; \\ 4. College of Resources and Environment, University of Chinese Academy of Sciences, Beijing 100049, China; \\ 5. Key Laboratory of Environment Change and Resources Use in Beibu Gulf, the Ministry of Education, \\ Guangxi Teachers Education University, Nanning 530001, China
}

\begin{abstract}
In this paper we establish a model that expresses the coupled relationship between grain yield and agricultural labor changes in China, and present a preliminary discussion of the coupled processes involved in changes in these factors at the county level. Thus, we develop two coefficients on the basis of county-level statistical data for grain yield and agricultural labor for the years 1991, 2000, and 2010, namely, the grain-labor elasticity coefficient (GLEC) and the agricultural labor-transfer effect coefficient (ALTEC). The results of this study show that during the transformation process of agricultural development in China, different kinds of coupled relationships between grain yield and agricultural labor changes co-existed at the same time. For example, between 1991 and 2010, counties characterized by three different coupled modes (i.e., increasing grain yield and decreasing agricultural labor, increasing grain yield and agricultural labor, and decreasing grain yield and agricultural labor) account for $48.85 \%, 29.11 \%$, and $19.74 \%$ of the total across the study area, respectively. Interestingly, a coupled relationship between increasing grain yield and decreasing agricultural labor is mainly concentrated in the traditional farming areas of China, while a coupled relationship between increasing grain yield and agricultural labor is primarily concentrated in pastoral areas and agro-pastoral ecotones in underdeveloped western China. At the same time, a coupled relationship between decreasing grain yield and agricultural labor is concentrated in areas that have experienced a rapid development transition in agriculture, especially the developed southeastern coast of China. The results of this study also show that between 1991 and 2010, 1961 counties experienced a decline in the proportion of agricultural labor; of these, 1452 are also characterized by increasing grain yield, $72.38 \%$ of the total. This coupled relationship between grain yield and changes in the proportion of agricultural labor shows a stepped fluctuation and has continually strengthened over time. Data show that mean values for the GLEC and ALTEC increased from -0.25 and -2.93 between 1991 and 2000 to -0.16
\end{abstract}

Received: 2017-03-28 Accepted: 2017-04-25

Foundation: Key Program of National Natural Science Foundation of China, No.41731286; The National Key Technology R\&D Program of China, No.2014BAL01B05

Author: Ge Dazhuan (1987-), PhD Candidate, specialized in agricultural transition. E-mail: gedz.15b@igsnrr.ac.cn

*Corresponding author: Long Hualou (1971-), PhD and Professor, specialized in rural restructuring, urban-rural devel-

opment and land use transition. E-mail: longhl@igsnrr.ac.cn 
and -1.78 between 2000 and 2010, respectively. These changes in GLEC and ALTEC illustrate that the influence of agricultural labor changes on increasing grain yields has gradually diminished. Finally, the results of this study reveal that the 'Hu Huanyong Line' is a significant boundary sub-dividing this coupled relationship between grain yield and changes in agricultural labor.

Keywords: grain yield; agricultural labor; agricultural transition; labor migration; 'Hu Huanyong Line'; coupled relationship

\section{Introduction}

The agricultural labor force is indispensable and important for grain yields (Qi, 2007; Long et al., 2016; Wu, 2010). However, since the 1990s, both grain yields and the agricultural labor force within China have varied rapidly (Zou et al., 2009). Grain yields, for example, increased from 435 million tons in 1991 to 546 million tons in 2010, while the agricultural labor force decreased from 0.35 billion people to 0.27 billion people over the same period. Furthermore, the proportion of non-agricultural employment and income from agricultural labor has increased (Li et al., 2013), while the methods in which the labor force participates in agricultural production has changed markedly (Zhang et al., 2011). Against this background of changes in agricultural labor, understanding the pattern and security of grain yields, as well as their coupled relationship with labor, are key research topics (Song et al., 2001; Chen et al., 2013; Wang et al., 2016).

Although research on the dynamic relationship between grain yields and agricultural labor has continued progress, a number of main points-of-view remain controversial (Chan, 2010; Taylor et al., 2010). For example, studies have argued that the transformation of agricultural labor has had a range of varied effects on grain production. Changes in grain yield are closely related to the supply of agricultural labor, manifested in several different ways. The first of these arguments states that when the supply of agricultural labor is sufficient, any transfer will not weaken grain-producing capacity, but will enhance the environment for agricultural production and increase grain yields (Chan et al., 1969; Lin, 2010). In contrast, a second argument states that limiting the supply of agricultural labor will lead to a rise in opportunity costs and a concomitant decrease in grain yields (Lipton, 1980; Clay et al., 1998). Thirdly, given free movement of the labor market, grain production will rely on supplementary inputs from other agricultural production factors following the complete transformation of agricultural surplus labor (Oseni et al., 2009; Gu, 2013).

The relationship between grain yields and the agricultural labor force in China has been researched in detail and has encompassed several different perspectives, including the factors that influence changes in grain yields (Zhang et al., 2011), the characteristics of agricultural labor transfer (Song et al., 2001), and the impacts of agricultural labor transfer on grain yields (Yan et al., 2011). Important recent progress has been made in the areas of food security given the background of urbanization (Christiansen, 2011), transformation of agricultural production modes under labor migration (Yan et al., 2016), the relationship between structural evolution of agricultural labor and grain production (Lu et al., 2008), and the impacts of rural depopulation on grain production (Long et al., 2012; Long, 2014).

In the context of a comprehensive analysis of grain yields and agricultural labor changes, it is clear that the bulk of previous research has investigated the unilateral rather than bilat- 
eral coupling between grain yields and changes in the agricultural labor force. While a large number of small-scale case studies have been carried out, few studies have addressed regional modes and the different factors involved in changes in grain yield and the supply of agricultural labor in China. Thus, the aim of this paper is to first determine the coupled relationship between grain yields and changes in agricultural labor based on existing research. Secondly, using the data for 1991, 2000, and 2010 at the county level, we present an analysis of patterns and the coupled relationship between grain yield and agricultural labor changes in different regions of China. Third, we test for the presence of theoretical coupling models using empirical evidence in order to provide suggestions for guiding adjustments in grain production policy.

\section{Materials and methods}

This paper mainly focuses on the coupled relationship between grain yields and agricultural labor changes across mainland China at the county level. We reveal the coupled relationship between these factors using theoretical models and empirical tests.

\subsection{The relationship between grain yields and agricultural labor}

\subsubsection{The coupled relationship between grain yields and agricultural labor changes}

Agricultural labor is indispensable for grain production. Under classical dual economic theory, Lewis (Lewis, 1989) and Ranis-Fei models (Ranis et al., 1969) have been used to map the process of labor transformation from traditional agricultural to modern production and have revealed the necessary conditions and effects of agricultural labor transfer on grain production. Thus, existing research demonstrates that the relationship between grain yields and changes in agricultural labor is affected by supply of the latter (Lipton, 1980; Oseni et al., 2009). Therefore, changes in agricultural labor can be used to characterize supply and reveal the coupled relationship between changes in grain yields and labor. In China, since the reform and opening-up policies were enacted in 1978, a number of characteristics defined changes in agricultural labor including regional increases and decreases. Building on previous analyses, three coupled models are developed in this paper between grain yields and changes in agricultural labor.

The coupled relationship between grain yield and changes in agricultural labor conforms to a Lewis-Fei-Ranis model given the context of an agricultural labor increasing zone (Ranis et al., 1969). Thus, the coupled relationship between grain yields and agricultural labor changes basically conforms with the reverse of dual economic structure transformation (Figure 1a). In other words, increasing agricultural labor over the period between $T_{1}$ and $T_{2}$ has enhanced mankind's ability to develop nature. Grain yields have therefore constantly increased as the scale of regional agricultural production has expanded as the result of increasing labor. However, at the same time, the marginal diminishing effect of grain production has also become increasingly obvious. On the basis of this model, agricultural labor productivity reaches a maximum and the effects of natural resource constraints become prominent at the point $T_{2}$. Subsequent to $T_{2}$, even if the volume of the available agricultural labor continues to increase, grain yields will stall and the relationship between food supply and demand will lead to severe social crises, necessitating urgent reforms of existing pro- 
duction relationships. As a result of this process, the coupled relationship between grain yields and agricultural labor changes enter a transitional period.

There are two coupled modes-of-relationship that concern grain yield and decreases in agricultural labor, one of which dominates in traditional agricultural zones (TAZs), while the other is prevalent in rapid agricultural transformation zones (RATZs). Different models of coupled relationships involve different processes, as illustrated in Figure 1b which highlights the coupled relationship between grain yields and decreases in agricultural labor in a TAZ. During the early stage of this process $\left(T_{1}\right)$, agricultural labor includes a high degree of surplus but at a low level of productivity, directly limiting grain yields. At this time, per capita grain occupancy remains low and is integrally linked to poverty in rural areas (De et al., 2005); the relationship between grain yields and agricultural labor is considered to be in an 'antagonism' stage at this point. In contrast, during the period between $T_{1}$ ' and $T_{2}$ ', urban areas come to the forefront of development and a 'Lewis' urban-rural dual structure is apparent. Affected by the costs of opportunity and comparative benefits, agricultural labor begins to transfer and non-agricultural employment is seen coupled with increasing non-farm incomes. This transition leads to structured employment and a gradual improvement in quality of life. Coupled with these developments, people also being able to obtain advanced technology as well as more funds which results in improvements in agricultural labor productivity and further increases in grain yields. All this has the effect of alleviating the so called 'man-land' and 'man-grain' interrelations characteristic of TAZs (Rozelle et al., 1999). Over the course of the period between $\mathrm{T}_{2}^{\prime}$ and $\mathrm{T}_{3}^{\prime}$, grain yields reach their highest point, $\mathrm{G}_{3}^{\prime}$, as agricultural labor decreases and productivity increases. Due to rapid urbanization and industrialization, labor productivity, agricultural production technology, and management systems are all continuously innovated, while the scale and specialization of agricultural production is continuously promoted (Wang et al., 2016). At the same time, marginal declines in the effects of agricultural production also come to the forefront; after point $\mathrm{T}_{3}^{\prime}$, for example, grain yields will decline because of the problem of rural 'hollowing' as the income gap widens between the urban and rural population. This process is accompanied by the widespread marginalization of agricultural land (Chen et al., 2009; Tian et al., 2010), which leads directly to widespread land abandonment (Chan, 2010).

The coupled relationship between grain yields and decreases in agricultural labor in RATZs (Figure 1c) conform to a dual economic structure model with respect to the relationship between the labor transfer and variations in agricultural output (Rains et al., 1969). However, both the economic basis and locations of RATZs are an improvement compared to those of TAZs, ensuring agricultural transformation. In other words, the more non-agricultural employment opportunities there are, the lower the opportunity cost to abandon grain production, which reduces the social security function of grain. In cases where declines in agricultural labor do not lead to decreases in grain yield between $T_{1}$ " and $T_{2}$ ", inputs of other production factors compensate for the impact of decreases in agricultural labor. During the process of regional economic transformation in China, agricultural production was lower in efficiency than other kinds of production; this was then gradually replaced by other industries, and regional grain self-protection capacity declined.

The three coupled relationships that exist between grain yields and changes in agricultural labor can occur simultaneously in different areas because of differences in levels of regional 

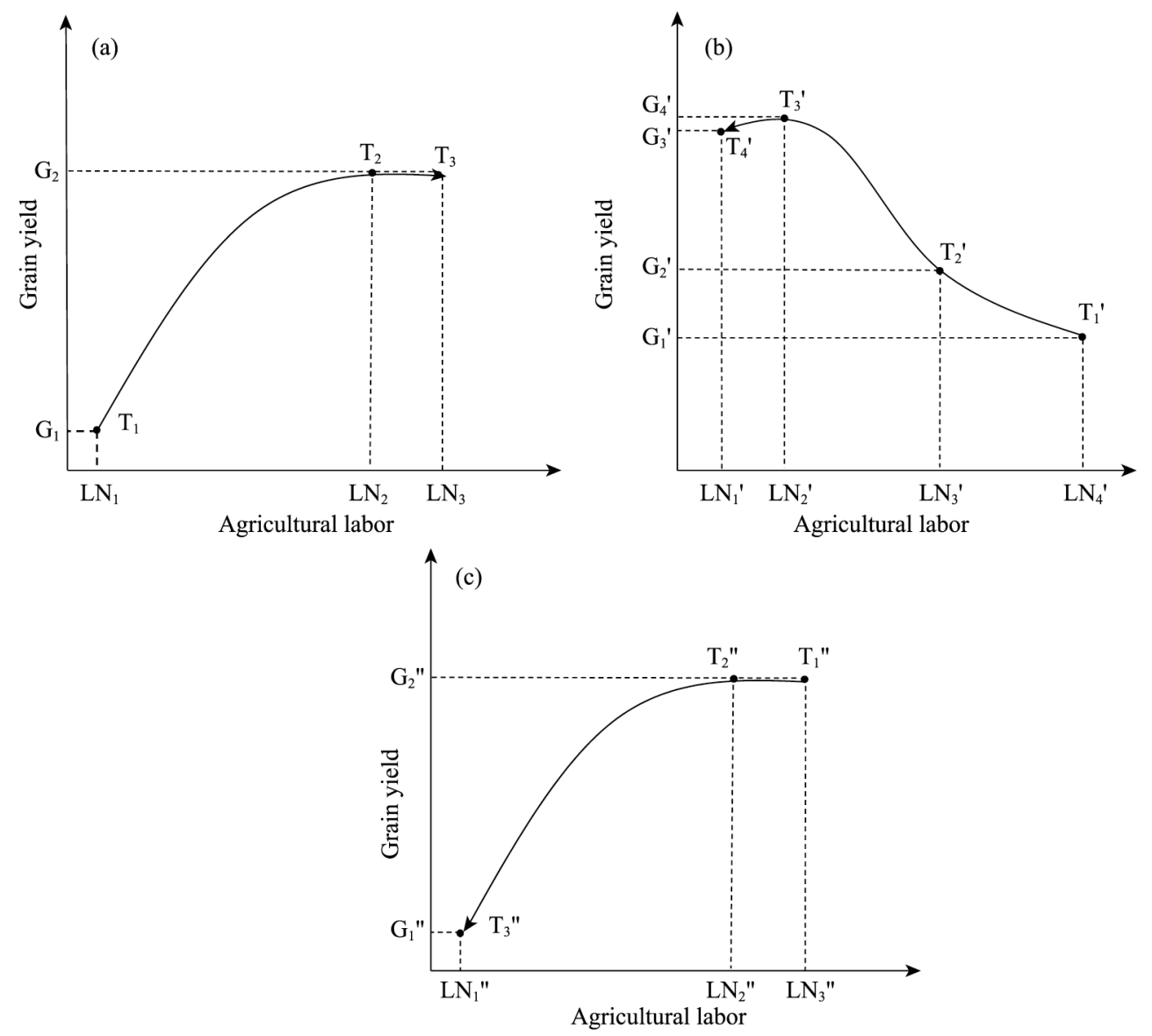

Figure 1 Conceptual models illustrating the coupled relationship between grain yields and changes in agricultural labor. Coupled models in agricultural labor increasing zones (a), traditional agricultural zones (b), rapid agricultural transformation zones (c).

development and location conditions. It is also noteworthy that these three coupled models can also appear continuously in the same region over different time periods; for example, agricultural labor first increased and then decreased as the result of regional agricultural transformation, before eventually being transferred. Thus, one of the aims of this paper is to reconstruct the couplings between grain yield and agricultural labor changes which characterize differences within the same and different time periods.

\subsubsection{The grain-labor elasticity coefficient (GLEC)}

The GLEC can be defined as the ratio between the rate of grain yield change divided by the rate of agricultural labor change over a given time period (Zou et al., 2009; Liu et al., 2010), The GLEC is calculated as follows:

$$
G L E C_{i}=\frac{G Y R_{i}}{A L N R_{i}}=\frac{\left(G Y_{i t 2}-G Y_{i t 1}\right) / G Y_{i t 1}}{\left(A L N_{i t 2}-A L N_{i t 1}\right) / A L N_{i t 1}}
$$

In this expression, $i$ denotes the county number, while $\mathrm{GYR}_{\mathrm{i}}$ and $\mathrm{ALNR}_{\mathrm{i}}$ refer to the rate of grain yield and the rate of agricultural labor number change respectively in a county, $i$. Thus, $\mathrm{GY}_{\mathrm{it} 2}$ and $\mathrm{GY}_{\mathrm{it} 1}$ refer to the grain yields of county $i$ during the time periods $t_{2}$ and $t_{1}$, 
while $\mathrm{ALN}_{\mathrm{it} 2}$ and $\mathrm{ALN}_{\mathrm{it} 1}$ denote agricultural labor in county $i$ during $t_{2}$ and $t_{1}$, respectively. Similarly, GLEC denotes the elasticity coefficient between grain yield and agricultural labor, which indicates a coupling relationship between grain yield changes and agricultural labor changes over the period between $t_{1}$ and $t_{2}$.

Thus, by analyzing changes in GLEC, the coupled relationship between grain yields and agricultural labor is revealed. In other words, if ALNR is greater than zero and GLEC is less than zero, an increase in agricultural labor and a decrease in grain yields is implied; increases in the former will have a reverse effect on the latter. Conversely, if ALNR and GLEC are both greater than zero, agricultural labor and grain yields vary in the same direction, and can explain the positive effect of increases in the former on the latter. In a case where both indexes are less than zero, agricultural labor decreases while grain output increases and the former has a positive effect on the latter. While if ALNR is less than zero and GLEC is greater than zero, decreases in agricultural labor will exert an inverse effect on increasing grain yield.

\subsection{The relationship between grain yields and the proportion of agricultural labor}

2.2.1 The coupled relationship between grain yields and changes in the proportions of agricultural labor

The coupled curve that expresses the relationship between grain yields and changes in agricultural labor proportion exhibits stepped fluctuations such that discrete trends are continually strengthened. In this context, agricultural labor refers to the number of people engaged in production within this sector, while proportion refers to rural employees, reflecting regional employment structure and labor transfer trends. The model shows that between $\mathrm{T}_{1}$ and $\mathrm{T}_{4}$, trends in agricultural labor passed through four 'initial-middle-late-immoderate' transfer stages, respectively, which determine the different coupling curves between grain yields and changes in agricultural labor proportions (Figure 2). Similarly, the coupled process between grain yields and agricultural labor proportion comprises three stages of 'agglomeration-discretization-reaggregation'. Previous work has shown that during the early stage of agricultural transformation, the labor proportion was generally high (Lin, 1992) and the coupled grain-labor curve conformed to a 'negative skew'. However, during the process of agricultural transformation and development, average grain yields obviously improved in concert with decreasing agricultural labor proportion and the coupled grain-labor curve continuously advanced alongside a low proportion of agricultural labor with increasing discrete trend.

Between $T_{1}$ and $T_{3}$, the model shows that transfer of agricultural labor had a positive effect on grain yields ( $\mathrm{Li}$ et $a l ., 2013$ ) which increased across China. Similarly, between $\mathrm{T}_{3}$ and $\mathrm{T}_{4}$, excessive transfer of agricultural labor led to the accumulation of grain production into more dominant regions, while the centralization and specialization trend in grain yields increased (Wang et al., 2016). The proportion of agricultural labor in RATZs declined rapidly at this time, and originally dominant grain-producing areas were partially withdrawn from grain production. Nevertheless, underdeveloped regions with a higher proportion of agricultural labor retained some fractional grain-producing capacity because of the social 
security function of food (Tian et al., 2010). Results show that between $\mathrm{T}_{3}$ and $\mathrm{T}_{4}$, the declining agricultural labor proportion exerted an inhibitory influence on grain production (Heerink et al., 2007). The ongoing transfer of agricultural labor continues to threaten the safety of grain production, while the coupled relationship between grain yields and the labor proportion means that we are entering a new phase of adjustment.

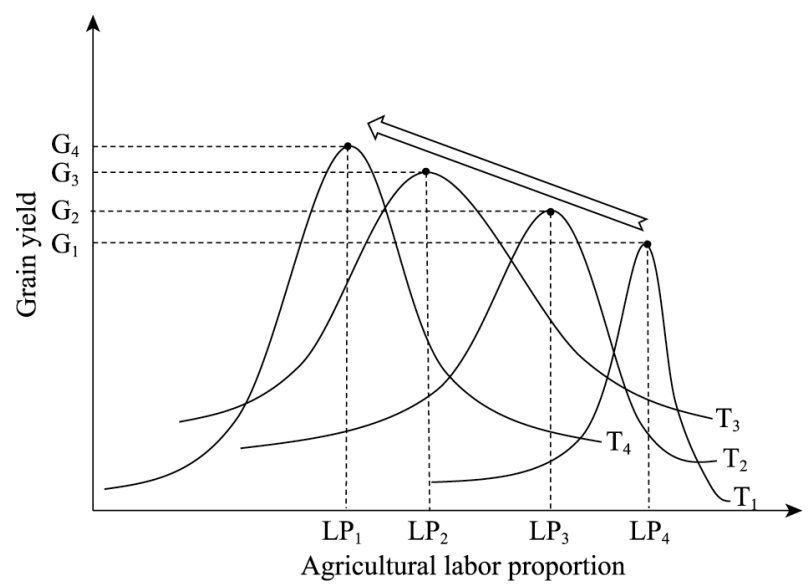

Figure 2 Conceptual model illustrating the coupled relationship between grain yields and changes in the proportion of agricultural labor at the county level

\subsubsection{The agricultural labor-transfer effect coefficient (ALTEC)}

The transfer effects of agricultural labor include shifts from agricultural production to non-agricultural production as well as regional transboundary shifts. Thus, one of the aims of this paper is to determine the ALTEC and utilize it to describe the influence of the transfer of agricultural labor on regional grain yields. ALTEC is calculated as follows:

$$
A L T E C_{i}=\frac{G Y R_{i}}{A L P R_{i}}=\frac{\left(G Y_{i t 2}-G Y_{i t 1}\right) / G Y_{i t 1}}{\left(\frac{A L N_{i t 2}}{R E N_{i t 2}}-\frac{A L N_{i t 1}}{R E N_{i t 1}}\right)}
$$

In this expression, $i$ denotes county number, while $G Y R_{i}$ and $A L P R_{i}$ represent rates of change in grain yield and the proportion of agricultural labor, respectively. Similarly, $G Y_{i t 2}$ and $G Y_{i t 1}$ refer to the grain yield of a county $i$ during time periods $t_{2}$ and $t_{1}$, respectively, while $A L N_{i t 2}$ and $A L N_{i t 1}$ denote the agricultural labor number, and $R E N_{i t 2}$ and $R E N_{i t 1}$ denote the rural employees of county $i$ during the period between $t_{2}$ and $t_{1}$, respectively. Values of ALTEC therefore explains the coupled relationship between grain yields and changes in the proportion of agricultural labor.

Thus, if ALTEC is greater than zero then changes in grain yields will exhibit the same trend as the agricultural labor proportion, but if grain yield increases and ALPR is greater than zero then the increasing agricultural labor proportion will have a positive effect on grain yield. In contrast, if ALPR is less than zero and grain yields are also reduced then declines in the proportion of agricultural labor will act to inhibit grain production. Similarly, if ALTEC is less than zero and ALPR is greater than zero when grain yields decrease, this could indicate that increases in the agricultural labor proportion will exert an obstructive effect on grain production. Finally, if ALPR is less than zero and the grain yield increases, 
decreases in the proportion of agricultural labor will exert a positive effect on grain production.

\subsection{Data}

The data used in this paper include agricultural labor statistics, the number of rural employees, and total grain yields for the years 1991, 2000, and 2010. Data for 1991 were provided by the China Natural Resources Data Center (http://www.data.ac.cn), while those for 2000 and 2010 come from the China County (City) Social and Economic Statistical Yearbook. Thus, with the exception of counties where statistical data is absent, this paper includes a total of 2,006 effective statistical units. The basic geographical data we used are derived from the Resource and Environment Science Data Center of the Chinese Academy of Sciences (http://www.resdc.cn/). Because administrative divisions at the county level across China were continuously adjusted between 1991 and 2010, those used in this study are adjusted against standard divisions of 2010 .

\section{Results}

\subsection{Coupling between grain yields and changes in agricultural labor}

\subsubsection{Coupling between grain yields and changes in agricultural labor at the county level}

Characteristics of spatial coupling between grain yields and agricultural labor in China are obvious; in places where there is more agricultural labor, grain yields are higher. In addition, the 'Hu Huanyong Line' (the 'Hu Line') determines the nature of this spatial pattern (Figure 3). To the southeast of the 'Hu Line', agricultural labor and grain yields are higher than to the northwest, especially within river alluvial plains, while in contrast, to the northwest of this line, the proportion of agricultural labor is generally low and grain yields are very limited. These characteristic spatial couplings between grain yield and agricultural labor across China are inseparable from physical factors, including water, soil, air temperature, and heat, as well as the spatial distribution pattern of population (Figure 3).

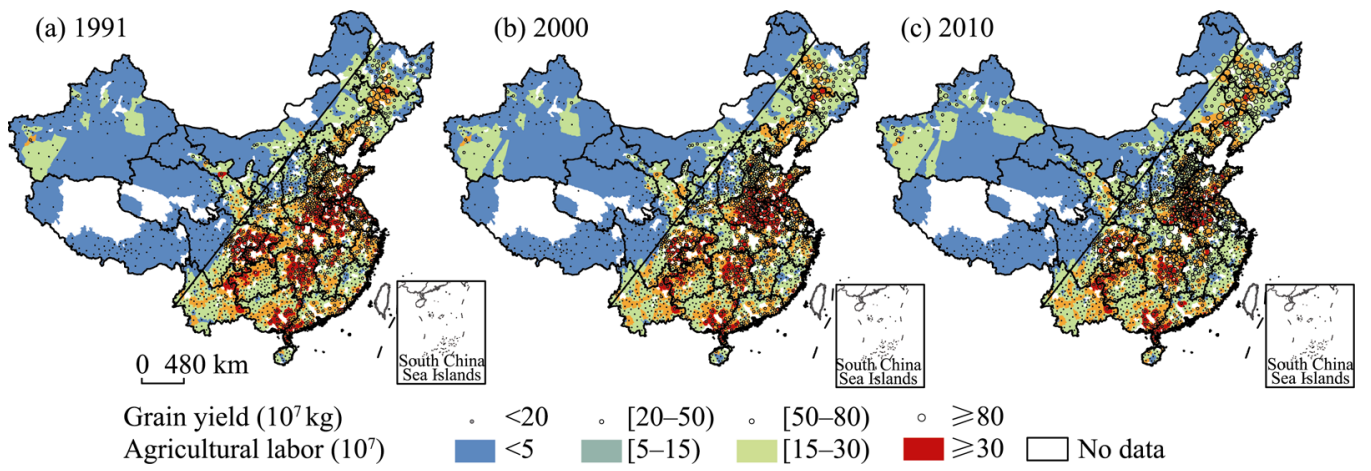

Figure 3 Maps showing the spatio-temporal pattern in the coupled relationship between grain yields and agricultural labor at the county level over the period between 1991 and 2010

3.1.2 Spatio-temporal coupling between grain yields and changes in agricultural labor at the county level

(1) GLEC spatial characteristics between 1991 and 2000 
Between 1991 and 2000, agricultural labor decreased in 1078 counties mainly located to the southeast of the 'Hu Line' (Figure 4a). Of these, 363 were characterized by decreasing grain yields (i.e., ALNR less than zero and GLEC greater than, or equal to, zero) and are mainly distributed in Zhejiang Province and on the eastern Shandong Peninsula. A total of 715 counties were characterized by increasing grain yields (i.e., ALNR and GLEC less than zero), mostly concentrated in areas including the Huang-Huai-Hai Plain and Sichuan Basin. At the same time, 712 counties exhibited increases in both agricultural labor and grain yields (i.e., ALNR greater than zero and GLEC greater than, or equal to, zero), mostly located in the central and western parts of Xinjiang Uygur Autonomous Region (Xinjiang), on the Yunnan-Guizhou Plateau, in the Henan-Shandong-Anhui junction area, and in the west of Sichuan Province (Figure 4d). A further 228 counties are characterized by increasing agricultural labor and decreasing grain yields (i.e., ALNR greater than zero and GLEC less than zero), mainly scattered in northern Qinghai and western Liaoning provinces. Indeed, over the time period of this survey, counties characterized by 'increasing grain yields and agricultural labor', 'decreasing grain yields and agricultural labor', 'increasing grain yields and decreasing agricultural labor', and 'decreasing grain yields and increasing agricultural labor' comprise $35.54 \%, 18.09 \%, 35.64 \%$, and $10.72 \%$, respectively, of the total number.
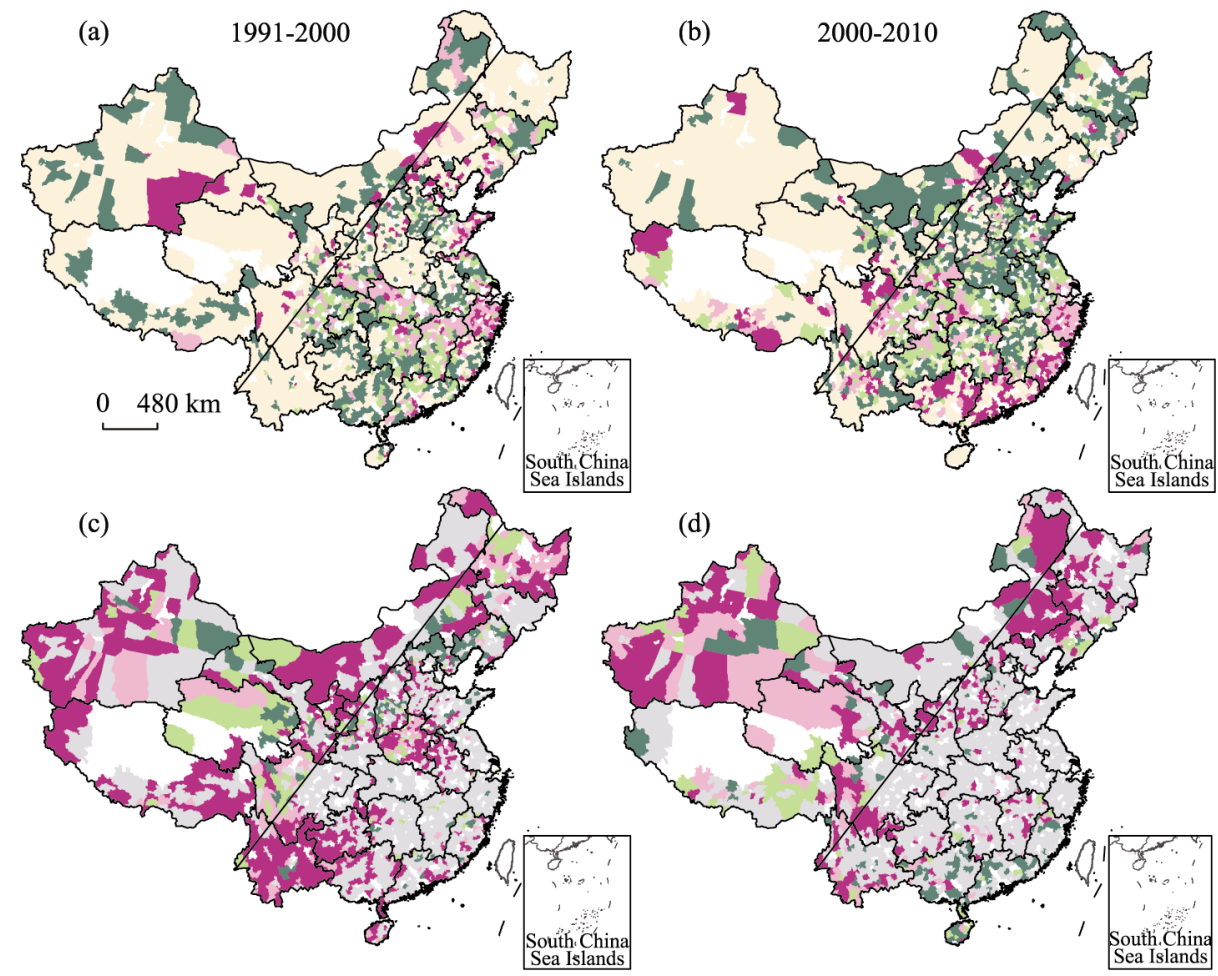

(d)
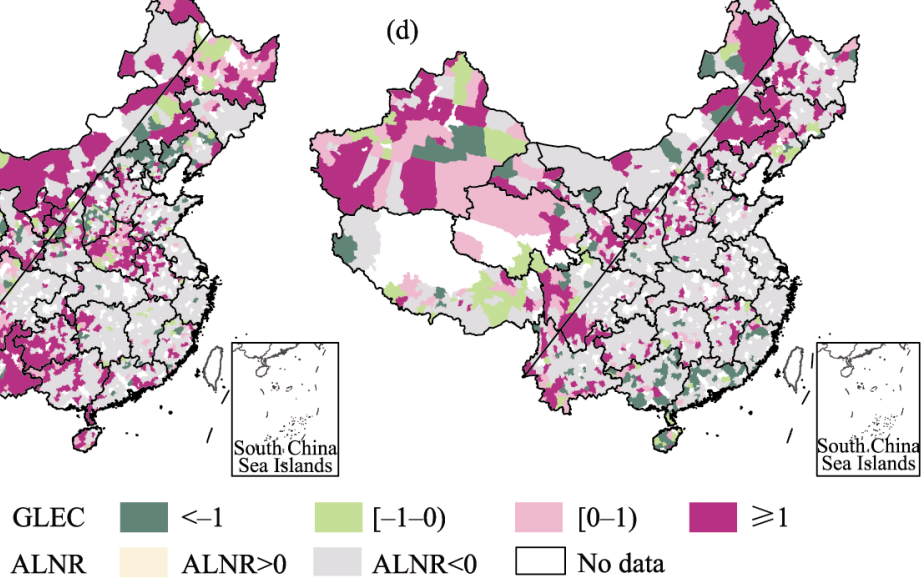

Figure 4 Maps showing spatio-temporal patterns of GLEC at the county level between 1991 and 2010

(2) GLEC spatial characteristics between 2000 and 2010

Between 2000 and 2010, results show that 1385 counties experienced a decrease in agricultural labor, mainly in eastern China (Figure 4b). Of these, 482 saw a decrease in grain 
yield (i.e., ALNR less than zero and GLEC greater than, or equal to, zero) and are mainly scattered in the southeastern coastal provinces and Guangxi Province, while 903 counties accounting for $45 \%$ of the total experienced an increase in grain yields (i.e., ALNR and GLEC less than zero), principally located on the Huang-Huai-Hai Plain, in the Hetao area, and on the northeastern plain. At the same time, 432 counties chiefly concentrated in Xinjiang and eastern Inner Mongolia experienced an increase in both agricultural labor and grain yields (i.e., ALNR greater than zero and GLEC greater than, or equal to, zero) (Figure 4d); of these, just 189 counties mostly distributed in eastern Tibet and in Hainan Province experienced an increase in both agricultural labor as well as a decrease in grain yields (i.e., ALNR greater than zero and GLEC less than zero). Counties at this time that are characterized by 'increasing grain yield and agricultural labor', 'decreasing grain yield and agricultural labor', 'increasing grain yield and decreasing agricultural labor', and 'decreasing grain yield and increasing agricultural labor' accounted for $21.54 \%, 24.03 \%, 45.01 \%$, and $9.42 \%$ of the totals, respectively.

3.1.3 The evolution and classification of the coupled relationship between grain yields and changes in agricultural labor

Changes in GLEC show that the effects of agricultural labor changes on grain yields both decline and exhibit significant regional differences. Results show that between 1991 and 2010, the average GLEC value rose from 3.81 to 3.99 in counties characterized by increasing agricultural labor. This result indicates that the effect of increasing agricultural labor on grain yields is still present in less developed areas; however, between 2000 and 2010, this county type decreased to just 307 with grain yields accounting for $41.22 \%$ of the total in 2000 , before falling further to $25.81 \%$ in 2010 . Over the same period, the average GLEC values of counties characterized by decreasing agricultural labor increased from -2.56 to -1.76 , which shows that the effect of decreases in this factor on enhancing grain production also declined. Grain yields in this county type accounted for $58.78 \%$ of total yields in 2000 , increasing to $74.19 \%$ in 2010 , becoming the major coupling between these two factors. Against the background of an overall decline in the availability of agricultural labor, average GLEC across China rose from -0.25 between 1991 and 2000 to -0.16 between 2000 and 2010. This increase is indicative of the positive effect of agricultural labor decreases on declines in grain production. As a result, the role of agricultural labor in promoting grain production has gradually declined in China while the role of non-labor-related factors continues to strengthen (Gao et al., 2012; Chen et al., 2013; Shao et al., 2014). Spatial patterns within the coupled relationship between grain yields and agricultural labor also reveal a number of obvious regional differences, with the 'Hu Line' acting as a large-scale GLEC boundary. Counties that exhibit a coupled relationship in the opposite direction are located mainly to the southeast of the 'Hu Line' (exception of developed areas in the southeastern coastal region of China), where agricultural labor is decreasing and grain yields are simultaneously increasing. Similarly, counties that exhibit a coupled relationship in the same trend direction are mostly concentrated to the northwest of the 'Hu Line', characterized by increases in both grain yields and agricultural labor (Heerink et al., 2007).

Because of agricultural transformation and development, different coupled relationships co-exist simultaneously between grain yields and changes in agricultural labor in different regions. This phenomenon is one distinguishing feature of Chinese agricultural transforma- 
tion and development that is different to other countries. Indeed, coupled relationships between increasing agricultural labor and grain yields are mainly seen in under-developed pastoral regions and in the agro-pastoral ecotones of western China, while coupled relationships between increasing grain yields and decreasing agricultural labor are mainly concentrated in traditional farming areas which account for the highest total grain yields countrywide. Coupled relationships between decreasing grain yields and agricultural labor are seen in areas that have experienced rapid transitions in agricultural development, especially in developed southeastern coastal China, a region characterized by much more employment in non-agricultural sectors as well as a gradual withdrawal from grain production. Because these coupled relationships also reveal regional differences in agricultural transformation and development processes, it is necessary to formulate differentiated policies to address regional grain production security.

\subsection{Coupling between grain yields and changes in agricultural labor proportions}

\subsubsection{Coupling between grain yields and agricultural labor proportions at the county level}

Spatial coupling patterns between grain yields and agricultural labor proportions are shown in Figure 5. These data show that in 1991, the proportion of agricultural labor in China was generally high (mean: $84.12 \%$ ) and that counties with high grain yields were mainly distributed in the middle and lower reaches of the Yangtze Plain, on the Huang-Huai-Hai Plain, and in the Sichuan Basin. Indeed, with the exception of the Yangtze and Pearl River deltas, major grain producing areas were also characterized by a higher proportion of agricultural labor. However, by 2000 , the proportion of agricultural labor in China had fallen to $74.28 \%$, and the coupled relationship between grain yields and proportions of agricultural labor showed obvious differences both sides of the 'Hu Line'. Results show, for example, that the proportion of agricultural labor decreased while grain yields did not fall significantly to the southeast of this line. At the same time, the proportion of agricultural labor was maintained at a high level and grain yields were stable northwest of the 'Hu Line' (Figure 5). By 2010, the proportion of agricultural labor in the middle and lower reaches of the Yangtze Plain as well as in southeastern coastal provinces declined rapidly, especially in the Yangtze and Pearl River deltas, concomitant with rapid decreases in grain yields in these areas.

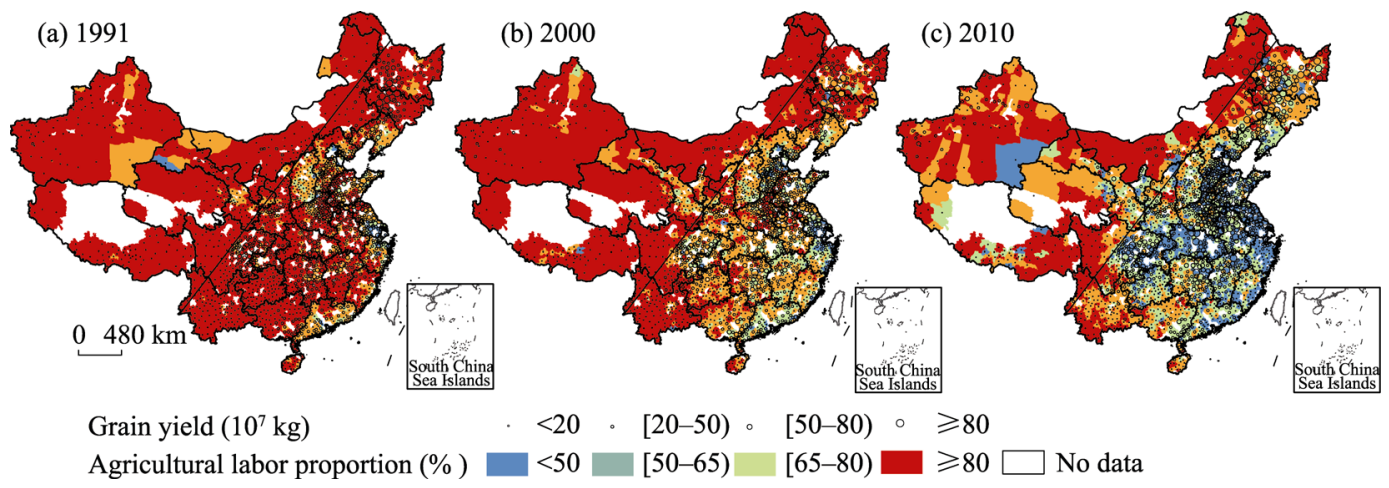

Figure 5 Maps showing spatio-temporal patterns in the coupled relationship between grain yields and agricultural labor proportions at the county level between 1991 and 2010

The curve illustrating the coupled relationship between grain yields and changes in agri- 
cultural labor proportions reveals stepped fluctuations (Figure 6). Taking the range in agricultural labor proportion as the abscissa, we calculated the proportion of counties and grain yields with a different range of agricultural labor compared to the total counties and grain yields, and referred to these values as 'county proportion' and 'grain yield proportion', respectively. The data presented in Figure 6 reflect dynamic changes in county and grain yield proportions for each section and show peaks within the same range as well as a trend towards downstream sections with declining peak values. Over the period between 1991 and 2000, agricultural labor force proportions greater than $80 \%$ and between $60 \%$ and $90 \%$ characterize $71.79 \%$ and $76.72 \%$ of total counties and generated $65.95 \%$ and $69.53 \%$ of total grain yields. At the same time, a synchronous peak in county and grain yield proportions appeared within the range between $80 \%$ and $90 \%$ and between $70 \%$ and $80 \%$ of the agricultural labor proportion, respectively. In 2010, the proportion of agricultural labor that fell between $40 \%$ and $60 \%$ reflects peaks in county and grain yield proportions. While the average proportions of agricultural labor in China decreased and coefficients of variation were $13.20 \%, 18.36 \%$, and $29.08 \%$ in 1991,2000 , and 2010, respectively. Average grain yield proportions and standard deviations also increased over this period; all-in-all, a discrete trend that reflects a coupled relationship between grain yields and the proportion of agricultural labor was continually strengthened throughout the survey period.
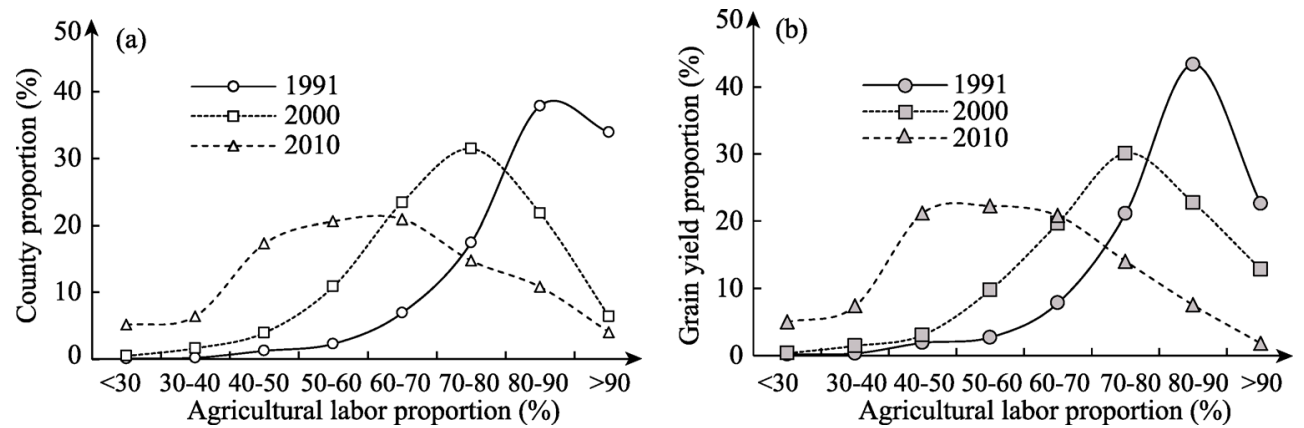

Figure 6 Number of counties and grain yield proportions given differences in agricultural labor at the county level across China

3.2.2 Spatio-temporal characteristics in the coupled relationship between grain yields and changes in the proportion of agricultural labor at the county level

The coupled relationship between grain yields and changes in the proportion of agricultural labor reveals a number of distinct regional differences. Data presented in Table 1 illustrates the proportion of counties that show different coupling relationships between grain yields and changes in the proportion of agricultural labor during different periods. These data show that county-level proportions of agricultural labor decreased while grain yields increased (i.e., ALPR and ALTEC values less than zero) in more than $62 \%$ of the different periods (Figures $7 \mathrm{a}$ and $7 \mathrm{~b}$ ). This coupled relationship is dominant and suggests that, in most counties, transfer of agricultural labor had a positive effect on promoting grain yields. Counties of this type are mainly distributed on the Huang-Huai-Hai Plain, and also include three provinces in northeastern China and Inner Mongolia. At the same time, however, the proportion of counties characterized by both a decrease in the proportion of agricultural labor and grain yields (i.e., ALPR less than zero and ALTEC greater than, or equal to, zero) make up nearly $25 \%$ of the total and are mainly located in the Yangtze and Pearl River deltas as well 
as in southeastern coastal areas. These regions have been at the forefront of Chinese socio-economic development and the transfer of agricultural labor has had an obviously reverse effect on grain production (Chen et al., 2007). In addition, a small number of counties are also characterized by increases in the proportion of agricultural labor (Figures $7 \mathrm{c}$ and $7 \mathrm{~d}$ ), although regions where this coupling occurs do not cluster together.

Table 1 Classification statistics illustrating the ALTEC at the county level between 1991 and 2010

\begin{tabular}{cccc}
\hline & ALTEC & 1991 to $2000(\%)$ & 2000 to 2010 (\%) \\
\hline \multirow{2}{*}{ ALPR $<0$} & ALTEC $\geqslant 0$ & $25.98(521)$ & $31.16(625)$ \\
& ALTEC $<0$ & $65.2(1,308)$ & $62.87(1,261)$ \\
\hline \multirow{2}{*}{ ALPR $>0$} & ALTEC $\geqslant 0$ & $5.88(118)$ & $3.54(75)$ \\
& ALTEC $<0$ & $2.94(59)$ & $2.24(45)$ \\
\hline
\end{tabular}

Note: Numbers in parentheses indicate the number of counties that belong to each coupled type

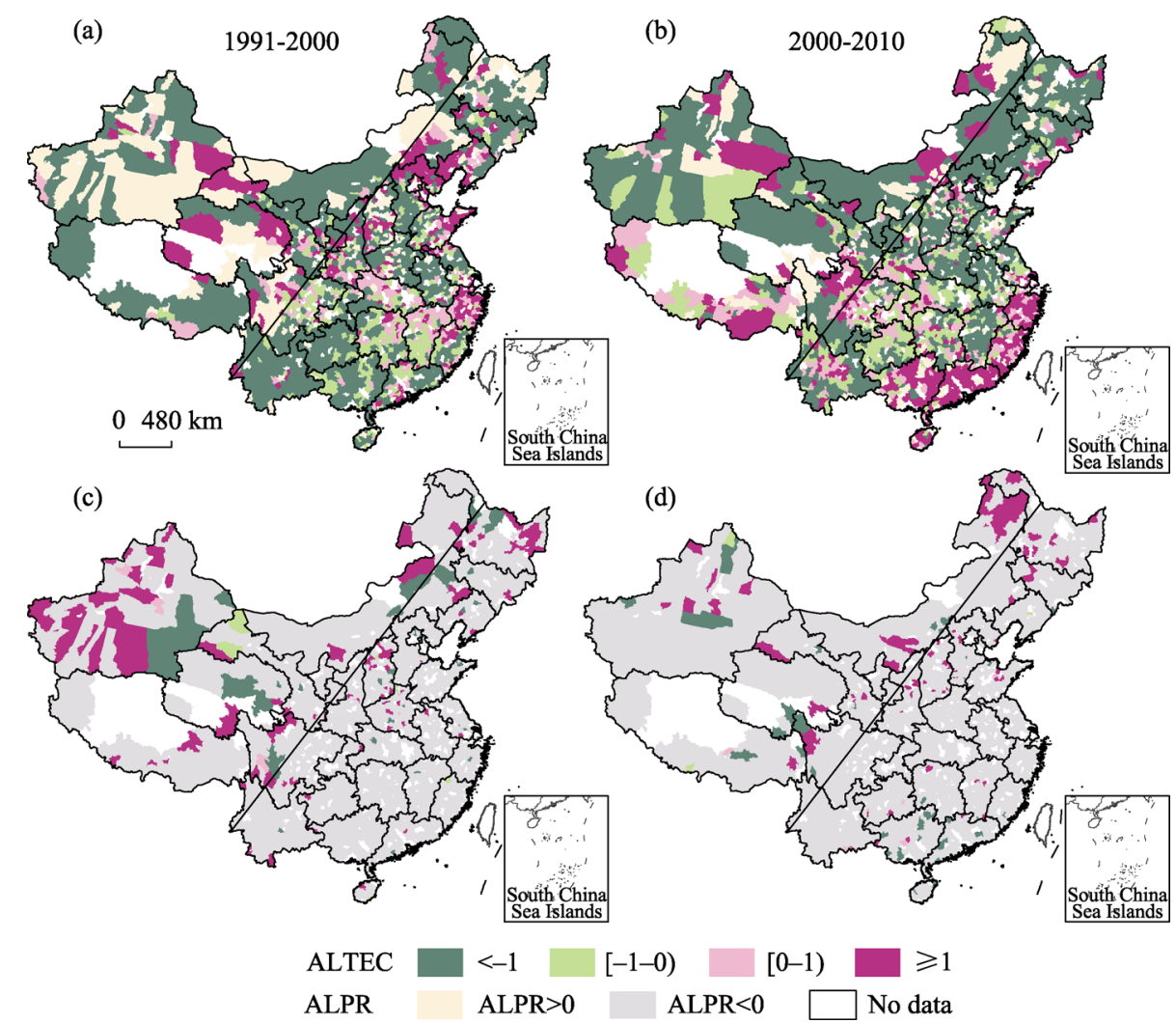

Figure 7 Maps showing spatio-temporal patterns in the ALTEC at the county level between 1991 and 2010

Results show that between 1991 and 2010, the coupled relationship between grain yields and changes in the proportion of agricultural labor exerted a positive influence on grain production, although differences in spatial patterns were also evident. Subsequent to the 1990s, more than $90 \%$ of counties experienced a decline in the proportion of agricultural labor. Data show that the mean ALTEC value rose from -2.93 between 1991 and 2000 to -1.78 between 2000 and 2010, indicating a gradual reduction in the effect of transferred agricultural labor. At the same time, a 'non-grain' trend also characterizes southeastern coastal regions while 
river delta regions have transitioned into urbanized regions from originally grain-producing areas. Because these phenomena have tended to partially weaken Chinese grain-producing capacity, if reasonable policy and measures are not enacted to guide this process then the positive effects of agricultural labor transfer on grain yields may be weakened. It is therefore necessary to protect Chinese food security from the negative impacts of excessive agricultural labor transfers (Zhang et al., 2011).

\section{Discussion and conclusions}

Data show that between 1991 and 2010, counties characterized by three different coupled models (i.e., increasing grain yields and decreasing agricultural labor, increasing grain yields and agricultural labor, and decreasing grain yields and agricultural labor) account for $48.85 \%, 29.11 \%$, and $19.74 \%$ of the total Chinese counties, respectively. Results also show that the average GLEC for all counties increased from -0.25 between 1991 and 2000 to -0.16 between 2000 and 2010. At the same time, while average GLEC rose from 3.81 to 3.99 in counties where agricultural labor increased, grain yields also accounted for $41.22 \%$ and $25.81 \%$ of totals in 2000 and 2010 , respectively. The average GLEC of counties characterized by decreases in agricultural labor rose from -2.56 to -1.76 over this period, while their grain yields accounted for $58.78 \%$ of the total in 2000 and $74.19 \%$ of the total in 2010 .

We show that this coupled relationship between grain yields and changes in agricultural labor exhibits synchronous diversification. Thus, based on theoretical analyses and empirical research, the results of this paper highlight three coupled relationships between grain yields and agricultural labor in the pastoral and agro-pastoral ecotone, in traditional agricultural areas, and in the rapid agricultural transition zone. These three relationships have co-existed with one another over a long time period, while the 'Hu Line' represents a significant boundary delineating the coupled relationship between grain yields and changes in agricultural labor. Traditional agricultural areas characterized by this coupled relationship are mainly located to the southeast of the 'Hu Line' where agricultural labor decreases and grain yields increase. However, decreases in both grain yields and agricultural labor mainly characterize the rapid agricultural transition zone of southeastern coastal China, while a coupled relationship within pastoral and agro-pastoral ecotones is also seen to the northwest of the 'Hu Line' where both grain yields and agricultural labor increase.

The coupled curve between grain yields and changes in the proportion of agricultural labor exhibits stepped fluctuations but has been continually strengthened over time. Indeed, this coupled relationship between grain yields and changes in the proportion of agricultural labor has mainly been positive over time, indicating that the transformation of agricultural labor has had a positive effect on promoting grain yields albeit with different spatial patterns. Mean ALTEC values rose from -2.93 between 1991 and 2000 to -1.78 between 2000 and 2010, which implies that the transfer effect of agricultural labor has declined.

Compared with other countries, the agricultural labor market, land ownership, and man-land interrelations in China exhibit specific characteristics as regional socio-economic development levels as well as the social security function of grain differ markedly. The coupled relationship between grain yields and agricultural labor also exhibits significant regional differences. Thus, based on theoretical analyses and empirical research, this paper summarizes three coupled relationships between grain yields and agricultural labor changes 
as well as their main areas of distribution. Data show that there is a strong need to take significant geographical differences into account across China; even if regions are characterized by the same coupled relationships, staggered phenomena occur within different couplings.

Chinese food security and the transfer of agricultural labor are important current research topics. Based on the GLEC and ATLEC values, this paper describes the coupled relationship between grain yields and changes and proportions in agricultural labor. Analyses show that the overall effect of agricultural labor transfer is declining. At the same time, grain production organization mode, new types of agricultural management bodies, land resource managerial systems, and other new factors of grain production (Long et al., 2015) as well as their impacts on grain production are increasing. Given a market economic background, the factors influencing changes in grain production are also increasing, but because they interact with one another, it is difficult to quantitatively measure their degree of influence on agricultural labor. Thus, based on detailed natural environment and socio-economic data, quantitative description of the impacts of agricultural labor on grain yield changes will be a future research focus.

The coupled relationship between grain yields and changes in agricultural labor not only reflects processes of regional agricultural transformation, but also tracks the path and nature of regional spatial transformation and development. At present, nearly half of the Chinese population still lives in rural areas, and thus their survival and development remain closely associated with grain production. The social security function of grain determines the relationships between fair, efficient, current, and long-term social security and ecological protection as part of the processes of rural transformation and development. A sustainable rural development system (Long et al., 2016), which guarantees food security and promotes benign rural advancement, is thus an important factor in formulating future agricultural and rural policies in China.

\section{References}

Chan K W, 2010. A China paradox: Migrant labor shortage amidst rural labor supply abundance. Eurasian Geography and Economics, 51(4): 513-530.

Chen Y, Li X, 2013. Spatial-temporal characteristics and influencing factors of grain yield change in China. Transactions of the Chinese Society of Agricultural Engineering, 29(20): 1-10. (in Chinese)

Chen Y, Li X, Tian Y et al., 2009. Structural change of agricultural land use intensity and its regional disparity in China. Journal of Geographical Sciences, 19(5): 545-556.

Christiansen F, 2009. Food security, urbanization and social stability in China. Journal of Agrarian Change, 9(4): $548-575$.

Clay D, Reardon T, Kangasniemi J, 1998. Sustainable intensification in the highland tropics: Rwandan farmers' investments in land conservation and soil fertility. Economic Development and Cultural Change, 46(2): 351-377.

De Janvry A, Sadoulet E, Zhu N, 2005. The role of non-farm incomes in reducing rural poverty and inequality in China. CUDARE Working Paper 1001, Berkeley: University of California.

Gao L, Huang J, Rozelle S, 2012. Rental markets for cultivated land and agricultural investments in China. Agricultural Economics, 43(4): 391-403.

$\mathrm{Gu}$ L, 2013. Relative analysis of China's grain yield and influence factors based on criterion of least absolute deviation. Transactions of the Chinese Society of Agricultural Engineering, 29(11): 1-10. (in Chinese)

Heerink N, Qu F, Kuiper M et al., 2007. Policy reforms, rice production and sustainable land use in China: A 
macro-micro analysis. Agricultural Systems, 94(3): 784-800.

Lewis A W, 1989. Dual Economy. Beijing: Beijing Economic College Press. (in Chinese)

Li L, Wang C, Segarra E et al., 2013. Migration, remittances, and agricultural productivity in small farming systems in Northwest China. China Agricultural Economic Review, 5(1): 5-23.

Lin J Y, 1992. Rural reforms and agricultural growth in China. The American Economic Review, 82(1): 34-51.

Lipton M, 1980. Migration from rural areas of poor countries: The impact on rural productivity and income distribution. World Development, 8: 1-24.

Liu Y, Li Y, 2010. Spatio-temporal coupling relationship between farmland and agricultural labor changes at county level in China. Acta Geographica Sinica, 65(12): 1602-1612. (in Chinese)

Long H, 2014. Land consolidation: An indispensable way of spatial restructuring in rural China. Journal of Geographical Sciences, 24(2): 211-225.

Long H, 2015. Land use transition and land management. Geographical Research, 34(9): 1607-1618. (in Chinese)

Long H, Li Y, Liu Y et al., 2012. Accelerated restructuring in rural China fueled by 'increasing vs. decreasing balance' land-use policy for dealing with hollowed villages. Land Use Policy, 29: 11-22.

Long H, Tu S, Ge D et al., 2016. The allocation and management of critical resources in rural China under restructuring: Problems and prospects. Journal of Rural Studies, 47: 392-412.

Lu W, Mei Yan, Li Y, 2008. Regional change in China's grain production: Effects of labor-land ratio, off-farm employment opportunities and labor compensation. Chinese Journal of Population Science, (3): 20-28. (in Chinese)

Oseni G, Winters P, 2009. Rural nonfarm activities and agricultural crop production in Nigeria. Agricultural Economics, 40(2): 189-201.

Qi L, 2007. Development Economics. Beijing: Higher Education Press. (in Chinese)

Ranis G, Fei J C H, 1969. A theory of economic development. American Economic Review, 51(4): 533-565.

Rozelle S, Taylor J E, DeBrauw A, 1999. Migration, remittances, and agricultural productivity in China. The American Economic Review, 89(2): 287-291.

Shao J, Zhang S, Li X, 2014. Farmland marginalization in the mountainous area: Characteristics, influence factors and policy implications. Acta Geographica Sinica, 69(2): 227-242. (in Chinese)

Song J, Wang E, 2001. The mode and tendency of agriculture surplus labor force transformation in China. Chinese Journal of Population Science, (6): 46-50. (in Chinese)

Taylor J E, López-Feldman A, 2010. Does migration make rural households more productive? Evidence from Mexico. The Journal of Development Studies, 46(1): 68-90.

Tian Y, Li X, Chen Y et al., 2010. A review on research advances in farm labor migration and its impacts on farm land use. Journal of Natural Resources, 25(4): 686-695. (in Chinese)

Wang X, Han L, Huang J et al., 2016. Gender and off-farm employment: Evidence from rural China. China \& World Economy, 24(3): 18-36.

Wang X, Huang J, Rozelle S, 2017. Off-farm employment and agricultural specialization in China. China Economic Review, 42: 155-165.

$\mathrm{Wu}$ Y, 2010. Calculation on the elasticity of agricultural input-output in China: Based on spatial econometrics models. Chinese Rural Economy, (6): 25-37. (in Chinese)

Yan J, Yang Z, Li Z et al., 2016. Drivers of cropland abandonment in mountainous areas: A household decision model on farming scale in Southwest China. Land Use Policy, 57: 459-469.

Yan J, Zhang Y, Hua X et al., 2016. An explanation of labor migration and grain output growth: Findings of a case study in eastern Tibetan Plateau. Journal of Geographical Sciences, 26(4): 484-500.

Zhang X, Yang J, Wang S, 2011. China has reached the Lewis turning point. China Economic Review, 22(4): 542-554.

Zheng H, Tong J, Xu Y, 2007. Spatio-temporal changes of farmland resources and their driving forces in developed areas. Transactions of the Chinese Society of Agricultural Engineering, 23(4): 75-78. (in Chinese)

Zou J, Long H, 2009. The variation of farmland use and the security pattern of grain production in China since 1978. Journal of Natural Resources, 24(8): 1366-1375. (in Chinese) 